\title{
Combining hydraulic model, hydrogeomorphological observations and chemical analyses of surface waters to improve knowledge on karst flash floods genesis
}

\author{
F. Raynaud ${ }^{1}$, V. Borrell-Estupina ${ }^{1}$, S. Pistre ${ }^{1}$, S. Van-Exter ${ }^{1}$, N. Bourgeois ${ }^{2}$, A. Dezetter ${ }^{1}$, and E. Servat ${ }^{3}$ \\ ${ }^{1}$ University of Montpellier/IRD/CNRS - UMR5569, HydroSciences Montpellier, 2 Place Eugène Bataillon, \\ 34095 Montpellier CEDEX 5, France \\ ${ }^{2}$ MAYANE, 34980 Montferrier-sur-Lez, France \\ ${ }^{3}$ IRD - IM2E, 2 Place Eugène Bataillon, 34095 Montpellier CEDEX 5, France
}

Correspondence to: V. Borrell-Estupina (valerie.borrell@um2.fr)

Received: 15 April 2015 - Accepted: 15 April 2015 - Published: 11 June 2015

\begin{abstract}
During a flood event over a karst watershed, the connections between surface and ground waters appear to be complex ones. The karst may attenuate surface floods by absorbing water or contribute to the surface flood by direct contribution of karst waters in the rivers (perennial and overflowing springs) and by diffuse resurgence along the hillslopes. If it is possible to monitor each known outlet of a karst system, the diffuse contribution is yet difficult to assess. Furthermore, all these connections vary over time according to several factors such as the water content of the soil and underground, the rainfall characteristics, the runoff pathways. Therefore, the contribution of each compartment is generally difficult to assess, and flood dynamics are not fully understood. To face these misunderstandings and difficulties, we analysed surface waters during six recent flood events in the Lirou watershed (a karst tributary of the Lez, in South of France). Because of the specific chemical signature of karst waters, chemical analyses can supply information about water pathways and flood dynamics. Then, we used the dilution law to combine chemical results, flow data and field observations to assess the dynamics of the karst component of the flood. To end, we discussed the surface or karst origin of the waters responsible for the apparent runoff coefficient rise during flash karst flood.
\end{abstract}

\section{Introduction}

In France, flooding is the most destructive natural hazard (Gaume et al., 2004), both in terms of material damages and human casualties. In Mediterranean regions, these events are called flash flood because of the fast and violent reaction of basins to heavy convective storms coming from the sea. In order to alert and prevent these events, flood forecasting services use hydrological models and other operational tools (Borrell-Estupina et al., 2015). For now, even if these tools can provide a useful evaluation on the flood peak for most of the basins, including some karst basins, they are not transposable on every karst basins. Karsts are present on a large number of Mediterranean basins, so not being able to forecast extreme events on these basins is a worrying issue. Very recently, Coustau et al. (2012), Fleury et al. (2013) or
Borrell-Estupina et al. (2014) developed operational hydrological model or graphical tools for flash flood forecasting and vigilance. The use of these tools on the recent floods events of 2014 by the operational French services shows that they are very useful and allow an earlier anticipation of the answer of the karst basin in real time. Consequently, a better knowledge on the karst response to rainfall is one of the issues for supplying a better prevention from flash floods on the karst basins.

The response of the karst to heavy rainfall is difficult to assess because of its non-linearity due to the complexity and heterogeneity of this environment. Bonacci et al. (2006) and Bailly-Comte et al. (2009) detailed this response from a local point of view. Coustau et al. (2012) showed that when working at more global scale, it appears that the karst response to rainfall is strongly dependent of its filling at the begin- 
ning of the event. An empty aquifer will absorb large amount of the surface water, by infiltration or river losses, and so reduce the surface flood. When the karst is saturated, its outcrop will behave as an impervious terrain and promote runoff while its resurgences will contribute to the river flow, and then amplify the flood. For most of flash flood events, these two situations are observed consecutively. Karst flash floods, as we call a flash flood on a karstic basin, are often studied with a modelling approach. Coustau et al. (2012) developed a conceptual distributed model working on the Lez basin. This model works on reanalyses and for operational forecasting. Its limitation is that the model is not transposable on others karst basins for now. Makropoulos et al. (2008) used a multi model approach, with three models from a conceptual to a physical based model. These models are operational, but too site specific to be applied on others karst basins. Physical based models may be an alternative to allow transposition. However, these kinds of model work generally on a very local scale (local functioning of the karst) and their complexity make them unfitted for operational use (Bailly-Comte et al., 2012). Finally, other approaches as reservoirs model (Fleury et al., 2013), neural network model (Kong A Siou et al., 2011) or inverse modelling (Labat et al., 1999; Maréchal et al., 2008) have been used but these kinds of approach are used to simulate and forecast a karst spring discharge and not the surface flood. All these models work on the basins they have been implemented on, but some of them, needing to be fed by lots of measurements and calibrations, perform only in re-analysis (not in real time). Furthermore, transposing the model to others sites is an unsolved issue because of lack of data and/or of knowledge or the too strong specificity of the karsts.

In fact, for most of the cases the missing information is a real and accurate estimation of the karst contribution to the flood event. It is possible to monitor each karst spring, but despite the huge financial cost of such instrumentation these measures would not take account of diffuse contributions to the flood. To bring some elements of response to this key question, this paper proposes an alternative by sampling water from the flood and estimating with hydraulic and chemical analyses the proportion of water that comes from the karst. This method is possible because of the specific chemical signature of karst water.

\section{Site and data}

\subsection{The Lez hydrosystem}

The Lirou River is a tributary to the Lez River, a Mediterranean river located near the city of Montpellier (Southern France). It is connected with the Lez aquifer, a karst with a groundwater basin of $380 \mathrm{~km}^{2}$. It is composed by Jurassic limestones and dolomites highly karstified. The Triadou gauging station is located on the Lirou River straight after the confluence with the Terrieu River. It controls a $83 \mathrm{~km}^{2}$ topographic watershed. Because of its upstream location in regard to the city of Montpellier, the Triadou station is optimal to anticipate floods with a sufficient delay.

In the Triadou catchment, the landscape is dominated by two kinds of formations: limestone plateaus where the karst outcrops (30\% of the basin), and plains where the karst is covered by quasi impervious formations. Vegetation is essentially scrub (63\% of the basin), and crops (31\%), urban areas in the Triadou catchment represent less than $6 \%$ of the whole basin. During the dry season, only the Lez spring is flowing (perennial spring which is exploited for the city of Montpellier); however, numerous ephemeral springs exist on the basin, the most important being the Lirou spring which is flowing under heavy rainfall conditions.

\subsection{Flood events}

In the Southern France, the autumn 2014 was a very wet season and numerous convective storm episodes happened. On the Lez watershed, six flooding events were recorded. The effects of these storms were very impressive, mostly because of the saturation of the karst due to previous events. The most notables by the peak discharge were in September (29 September 2014, $350 \mathrm{~m}^{3} \mathrm{~s}^{-1}$ ), October (6 October $\left.2014,420 \mathrm{~m}^{3} \mathrm{~s}^{-1}\right)$ and November (28 November 2014 , $140 \mathrm{~m}^{3} \mathrm{~s}^{-1}$ ). The first two events have resulted in numerous material damages but hopefully no human casualties. Downstream, the Lez River crosses the city of Montpellier, with almost half a million of inhabitants, part of which is directly threatened by flood risk. It is a critical issue to predict these events in order to alert and protect the city against this destructive hazard.

\section{Methods}

\subsection{Chemical analyses and dilution law}

We took water samples from different locations along the Lirou River (Fig. 1). There are two types of water: karst spring water (Lirou, Castle and Fleurette springs), and river surface water (Terrieu, Triadou, Restinclières and Prades). In fact, water samples in Prades on the Lez River correspond mainly to the Lez karst spring as we assume for the rest of this study. The samples were taken during low flow, high flow (water rising and decreasing) and flood peak. Chemical analyses consisted in Calcium, Magnesium and Bicarbonate ions $\left(\mathrm{Ca}^{2+}, \mathrm{Mg}^{2+}\right.$ and $\left.\mathrm{HCO}_{3}^{-}\right)$, and physical parameters: $\mathrm{pH}$, temperature and Electro-Conductivity (EC).

In fact, surface water is a mix of karst water and runoff water. In order to determine the proportions of the mixture, we used the conservation law chemical dilution law. These equations are applied between an upstream (U) and a downstream (D) locations. 


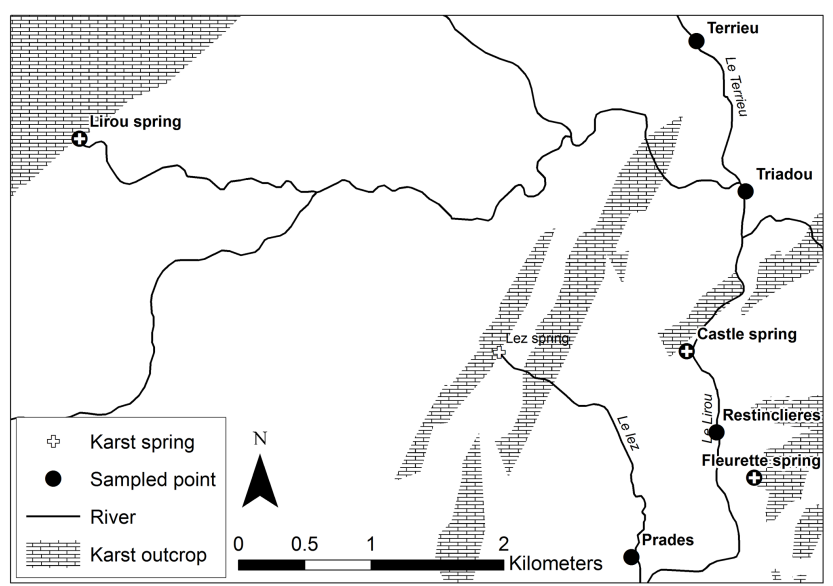

Figure 1. Sampled locations in the Lirou watershed.

Considering the flow at each location $\left(Q_{\mathrm{U}}\right.$ and $\left.Q_{\mathrm{D}}\right)$, and the value of a parameter or concentration $X\left(X_{\mathrm{U}}\right.$ and $\left.X_{\mathrm{D}}\right)$, we can apply:

$Q_{\mathrm{D}}-Q_{\mathrm{U}}=Q_{\mathrm{K}}+Q_{\mathrm{R}}$,

$Q_{\mathrm{D}} \cdot X_{\mathrm{D}}-Q_{\mathrm{U}} \cdot X_{\mathrm{U}}=Q_{\mathrm{K}} \cdot X_{\mathrm{K}}+Q_{\mathrm{R}} \cdot X_{\mathrm{R}}$,

where $\left(Q_{\mathrm{K}}, X_{\mathrm{K}}\right)$ and $\left(Q_{\mathrm{R}}, X_{\mathrm{R}}\right)$ are respectively the karst $(\mathrm{K})$ and runoff $(\mathrm{R})$ flow and concentration of the water input between the two locations. The aim of this study is to evaluate $Q_{\mathrm{K}}$ and $Q_{\mathrm{R}}$, but we cannot measure the concentration values for each component. As a consequence, we performed water analyses on various point in the basin where we knew the origin (karst or runoff) of the water. So the first step in our study will be to identify each compartment chemical signature to establish the typical signature of karst and runoff water $\left(X_{\mathrm{K}}\right.$ and $\left.X_{\mathrm{R}}\right)$. In this study, we computed the solutions of Eqs. (1) and (2) for four discriminating parameters: the Calcium, Magnesium and Bicarbonate concentrations and the Electro-Conductivity.

\subsection{Hydrogeomorphological observations and hydraulic model}

Acquiring samples during high flow and flood peak were not possible "directly" because of the short peak period and the dangers of sampling flood water. To deal with these difficulties, we sampled overflowing water and installed "water traps" (simple plastic bottles set at different stages along the river, on trees or river banks). Hydrogeomorphological observations during field investigations allowed us to guarantee the nature of the water we sampled on the bank of the river, and its possible contamination by another source of water. By observing water pathways, breach in the levee and flood marks, but also questioning flooded inhabitants, we were able to determine if the water is a remains of overflow of the river, or else runoff water. So we considered the water traps as a sample of the flood rising (the bottle will not mix water once
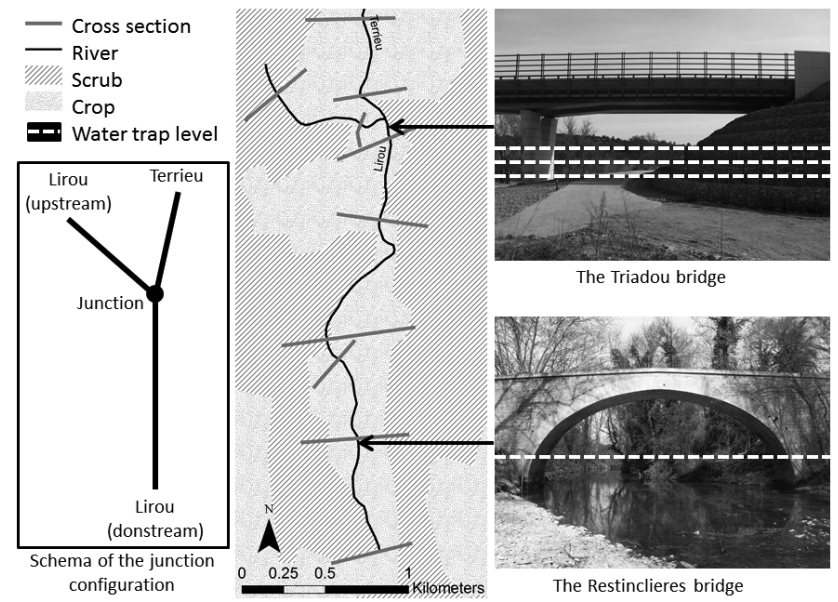

Figure 2. Topographic data used in HEC-RAS, and water trap level on two locations.

it is fulfilled), and the overflow as a mix of water around the flood peak.

To verify our observations about the water pathways, but also to associate a flow value to the overflow, we used a hydraulic model under the HEC-RAS model (http://www.hec. usace.army.mi). This model was also used to estimate the flow value corresponding to the water traps levels, and refine the curve rating for the Triadou gauging station. Figure 2 shows the cross sections used to define the topography of the model, and the level of the water traps on the Triadou and the Restinclieres Bridge.

\section{Results and discussions}

\subsection{Hydraulic in the Triadou gauging station and the Restinclieres site}

In order to estimate flow in the Triadou gauging station, we used the hydraulic model to convert the water depth measured by a pressure sensor to a flow. After a calibration of the Manning-Strickler coefficients with field observations, we obtained the curve rating on Fig. 3 (black line). A comparison with a previously existing curve rating established by simpler hydraulic laws applied on the real topography of the cross section (dashed line) shows that flow was overestimated for both high and low flow with the historical curve.

On Fig. 3 appear also the levels of each water trap (W. T.) and the levels reached for the 6 flood events in 2014 (vertical lines and arrowed segments). The hydraulic model was also used to estimate the flow necessary to fill in the water trap in Restinclieres, and overflow on left (L. O. B.) and right (R. O. B.) overbanks (horizontal lines). These results are consistent with our field observation during and after the flood events but we must underline here the large uncertainties that may bias the model (roughness calibration, initial conditions, junction and structure influences). In the future 


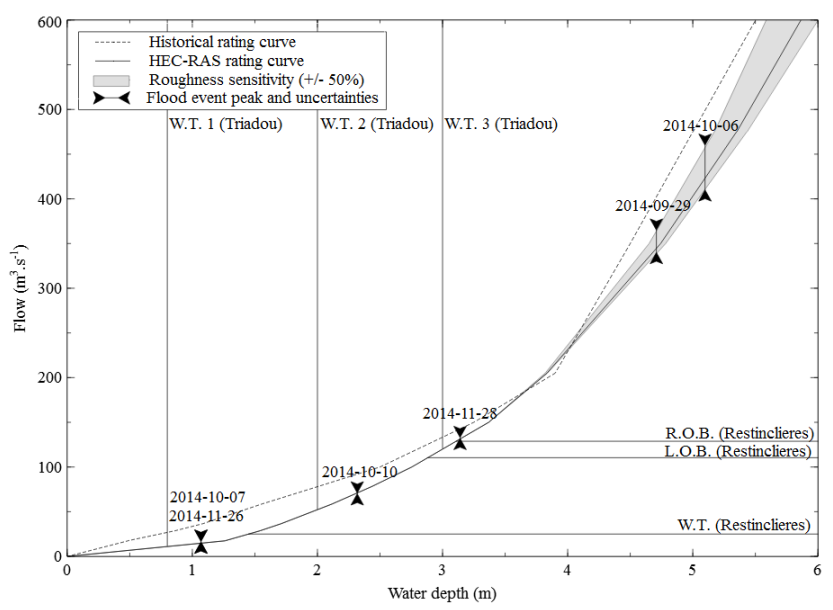

Figure 3. Rating curves, flood events and water trap flow obtained with the hydraulic model.

these uncertainties will be refined and precisely quantified to improve our model.

\subsection{Chemical signatures of the karst and runoff water}

In order to apply the dilution law to our samples, the first step is about finding chemical signatures for karst water and runoff water. Figure 4 illustrates how this first analysis allowed us to discriminate these "poles". We found for each parameter $\left(\mathrm{Ca}^{2+}, \mathrm{Mg}^{2+}\right.$ but also $\mathrm{HCO}_{3}^{-}$and E. C. $)$four distinct poles: the Lirou spring, the Fleurette and Castle spring, the Lez spring and the runoff pole.

Runoff is characterized by very low concentrations for each elements and a low electro-conductivity. On the one hand, the Lirou spring has a low concentration of Magnesium and a high concentration of Calcium. In fact, this is consistent with the nature of this spring: it is an overflowing spring, which means that the water from this spring is "young" (this water transited over a short time in the karst). The dissolution of dolomite (main source of Magnesium) is slower than the dissolution of calcite (Fairchild et al., 1996) so this result is coherent. On the other hand, the Lez spring is characterized by a high concentration in both Magnesium and Calcium. Because of the perennial nature of this spring, the results are consistent with an "old" water (this water stayed a long time in the karst aquifer). Finally, between these two kinds of karst spring, we can observe other springs, represented by an intermediate concentration between these two categories (here Fleurette and Castle springs).

If we group the karst spring poles, we can see a global karstic pole and a runoff pole. Between these to poles appear river samples, from the Lirou and Terrieu rivers. These samples are composed chemically by a mix of these two poles, around a probable mixing curve. At this point we can observe that peaks and rising water are very close to the runoff pole (a

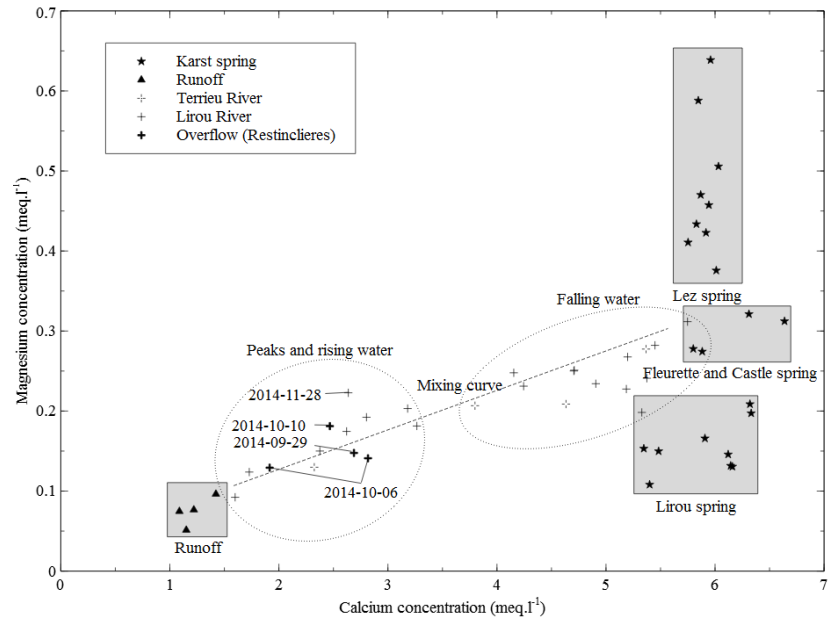

Figure 4. Calcium versus Magnesium concentration for each sample. Grey square defines the water poles, and dotted circle the moment of the sampling in the flood (main flood peaks are indicate by the date of the sampling).

probable dominance of runoff water in the river) while falling water are close to the karst poles.

\subsection{Estimation of the karst contribution to the flood}

Figure 5 shows the results obtained with the dilution law for each sample and the uncertainties associated. Horizontal error bars represent the uncertainties on the flow value for overflow samples (because the exact value is an approximation, see Fig. 3). Vertical error bars are due to the application of the dilution law.

These results show that the karst contribution to the surface flood varies in time during the flood. At the beginning of the flood (rising water), the karst contribution is high, around $80 \%$ of the surface flow. As the water level rises, this contribution fall quickly to less than $50 \%$, and for the flood peak this contribution is between 20 and $40 \%$ for peak higher than $50 \mathrm{~m}^{3} \mathrm{~s}^{-1}$. After the peak, when the water level falls, this contribution seems to progressively rise again toward $80 \%$. For the two higher peaks which represent both the 6 October 2014 event, the difference between the two dots is certainly due to a contamination by runoff water for the lower point sampled on the left overbank in Restinclieres, whereas the higher point was sampled on the right overbank. A closer examination shows that for the same flow value, the karst contribution during falling water is generally higher than during rising water. The karst contribution is not a function of the surface flow but depends on the time of the flood (and so piezometric level, cumulated rainfall and rainfall intensity). The results scattering shows us another variation between events of the karst contribution. So the variation of the karst contribution is time dependent during an event, but also dependent of the event. 


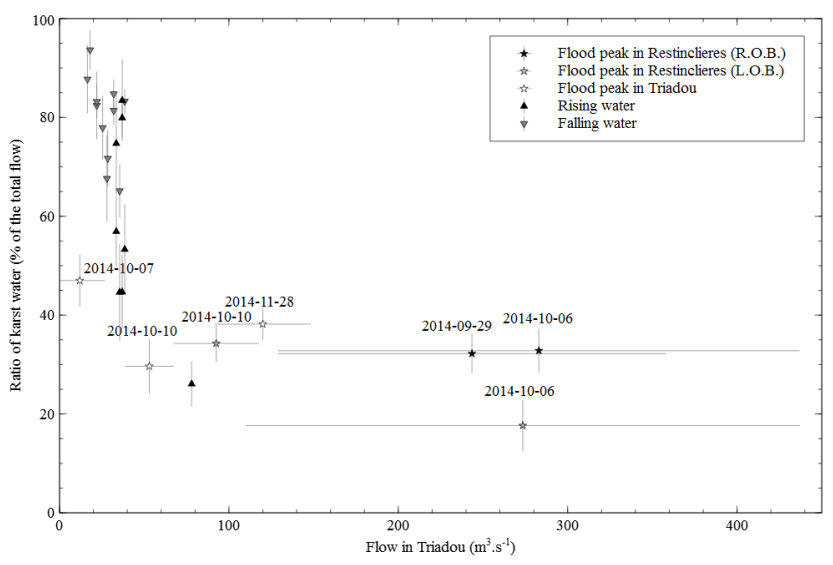

Figure 5. Ratio of karst water in river flow obtained with the dilution law (main flood peaks are indicate by the date of the sampling).

Figure 6 represents the hydrograph for the 6 October 2014 event, with an estimation of the karst flow computed with the mean results of the study (in grey) and the measured points (black cross). It is an illustration of the results we obtained in this study. During dry periods, the karst provides all the water in the river. When the first rainfall arrives, the river flow starts to rise up under both effects of runoff on impervious terrains (bellow $40 \%$ of the flow) and karst resurgences (under $60 \%$ ). While the rainfall continues, the karst aquifer tends to attain its saturation. As a consequence, the karst outcrops start to behave as impervious terrains and the runoff takes the advantage (up to $60 \%$ of the river flow), while the karst springs continue to contribute to the flood. Finally, when the rainfall stops, the runoff decreases until all surface water is drained and, in the end, the karst discharge contributes for the most part of the flow.

It is necessary to point out here the assumptions made to apply the dilution equations. Under steady flow conditions, the flow conservation equation is valid (derivation of the mass conservation) such as the concentration law (matter conservation). This is the case during low flow because the flow variations are negligible, and the parameters vary slowly, but for higher flow the validity of this assumption has to be discussed. Under unsteady flow conditions, the flow may vary quickly but also the parameters associated. In this study, we are assuming that this law is still valid during flood if we consider an uncertainty for both the flow measurement and the chemical parameters, and compute the equation within a "window" of values. So this work is to be seen under this strong assumption, but generally the value window is within the range of uncertainties specific to natural sciences.

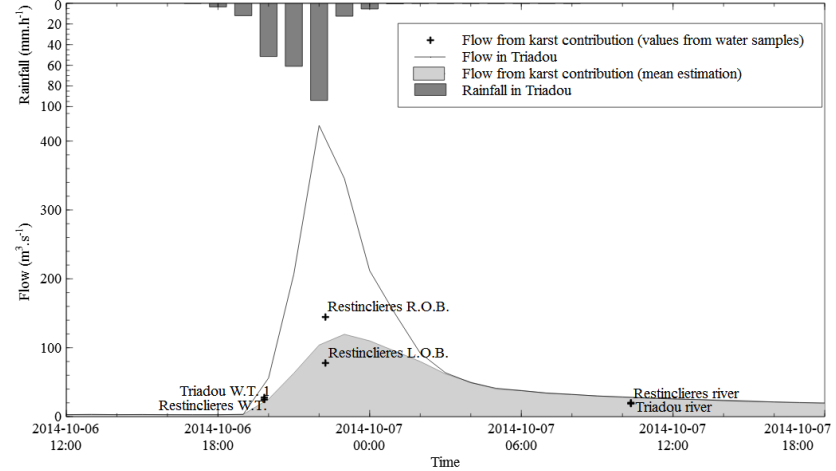

Figure 6. The October 2014 event hydrograph in the Triadou station with the estimated karst contribution (light grey hydrograph).

\section{Conclusions and prospects}

In this work, we developed an original methodology in order to estimate the karst contribution to the surface flash floods. This methodology is based on in situ observations and measures during the flood event or just after, to get hydrological and chemical information on the flood events. Then, we exploited these results by using simple conservation and mixture equations. We evaluated the global karst flow for different events at various time of the flood. Conceptually, these results are consistent with the common estimation of the karst during flood. During rising water, the ratio of karst water in the river discharge decreases progressively from 80 to $40 \%$. Around the flood peak, the runoff dominates and the karst contribution represents less than $40 \%$ of the river discharge. After the peak, the runoff contribution falls quickly and the karst contribution stays high. The ratio of karst water in the river is at its maximum for the flood.

Even if these results are very promising, we must insist on the limitations of this method. The first limitation is the relatively large range of uncertainties in this work. However, these uncertainties are not only caused by the method itself but mostly by the flow evaluation for very high water, and this limitation is not specific to our study but applies to every flood discharge evaluation. Moreover, these discharge uncertainties were carefully evaluated by using a hydraulic model in the first step. A second limitation is intrinsic with the hypothesis we made by applying the dilution law under unsteady flow conditions. However, we plan to investigate on this assumption by exploiting the hydraulic model to verify this particular point. We considered that, because of the velocity of the flood phenomena, we can consider chemical parameters as conservative. We believe it is a very small bias in our method (in regard to the discharge uncertainties) but this assumption will be verified as we continue our work on the method. Finally, this method has been for now applied only on the Lez basin, and we must test it on other karst basins to ensure its usefulness. That is actually the next step of our work, and sample campaigns have already been conducted 
on other basins. Hence, we will be able to evaluate the spatial variability of the karst contribution.

In the longer term, as it is the main goal of the project, we plan to propose hydrologic tools (models, methods) which will work on karst basins, and a set of recommendations to transpose a model from one karst site to another. The most important part of this work will be to understand how the karst responds to heavy rainfall (in a quantitative way) and to compare it with other hydrologic data (rainfall, piezometric levels, etc.) and models (a comparison of our results with a neural network model is presented in Darras et al., 2015). In this long term vision, we believe the method we presented here is an important breakthrough.

Acknowledgements. The authors thank the SPC Med-Ouest (French flood forecasting service) for its continuous financial and technical support, and the data it generously provided (topographic, meteorologic and hydrologic data) and the SYBLE (Lez watershed management agency) for the topographic data.

\section{References}

Bailly-Comte, V., Jourde, H., and Pistre, S.: Conceptualization and classification of groundwater-surface water hydrodynamic interactions in karst watersheds: Case of the karst watershed of the Coulazou River (Southern France), J. Hydrol., 376, 456-462, 2009.

Bailly-Comte, V., Borrell-Estupina, V., Jourde, H., and Pistre, S.: A conceptual semi distributed model of the Coulazou River as a tool for assessing surface water-karst groundwater interactions during flood in Mediterranean ephemeral rivers, Water Resour. Res., 48, W09534, doi:10.1029/2010WR010072, 2012.

Bonacci, O., Ljubenkov, I., and Roje-Bonacci, T.: Karst flash floods: an example from the Dinaric karst (Croatia), Nat. Hazards Earth Syst. Sci., 6, 195-203, doi:10.5194/nhess-6-195-2006, 2006.

Borrell-Estupina, V., Ladouche, B., Malaterre, P. O., Ricci, S., Caballero, Y., Coustau, M., Dörfliger, N., Fleury, P., Jay-Allemand, M., Marechal, J. C., and Thual, O.: Forecasting and mitigation of flooding in a Mediterranean karstic watershed, IAHS Publ., 363, 288-294, 2014.
Borrell-Estupina, V., Raynaud, F., Bourgeois, N., Kong-A-Siou, L., Haziza, E., and Servat, E.: Operational tools to help stakeholders to protect and alert municipalities facing uncertainties and changes in karst flash floods, IUGG Pragues 2015 proceedings, in press, 2015.

Coustau, M., Bouvier, C., Borrell-Estupina, V., and Jourde, H.: Flood modelling with a distributed event-based parsimonious rainfall-runoff model: case of the karstic Lez river catchment, Nat. Hazards Earth Syst. Sci., 12, 1119-1133, doi:10.5194/nhess-12-1119-2012, 2012.

Darras, T., Raynaud, F., Borrell-Estupina, V., Kong A Siou, L., Vayssade, B., Johannet, A., and Pistre, S.: Behaviour of Lez karst basin during flash flood events: neural network modelling and in situ measurements, IUGG Pragues 2015 proceedings, in press, 2015.

Fairchild, I. J., Tooth, A. F., Huang, Y., Borsato, A., Frisia, S., and McDermott, F.: Spatial and temporal variations in water and stalactite chemistry in currently active caves: a precursor to interpretations of past climate, Proceedings of the fourth International Symposium on the Geochemistry of the Earth's Surface, Ilkley, Yorkshire, July 1996, University of Leeds, Leeds, 229-233, 1996.

Fleury, P., Maréchal, J. C., and Ladouche, B.: Karst flash-flood forecasting in the city of Nîmes (southern France), Eng. Geol., 164, 26-35, 2013.

Gaume, E., Livet, M., Desbordes, M., and Villeneuve, J. P.: Hydrological analysis of the river Aude, France, flash flood on 12 and 13 November 1999, J. Hydrol., 286, 135-154, 2004.

Kong A Siou, L., Johannet, A., Borrell-Estupina, V., and Pistre, S.: Complexity selection of a neural network model for karst flood forecasting: The case of the Lez Basin (southern France), J. Hydrol., 403, 367-380, 2011.

Labat, D., Ababou, R., and Mangin, A.: Linear and nonlinear input/output models for karstic springflow and flood prediction at different time scales, Stoch. Environ. Res. Risk A., 13, 337-364, 1999.

Makropoulos, C., Koutsoyiannis, D., Stanić, M., Djordjević, S., Prodanović, D., Dašić, T., Prohaska, S., Maksimović, Ć., and Wheater, H.: A multi-model approach to the simulation of large scale karst flows, J. Hydrol., 348, 412-424, 2008.

Maréchal, J. C., Ladouche, B., and Dörfliger, N.: Karst flash flooding in Mediterranean karst, the example of Fontaine de Nîmes, Eng. Geol., 99, 138-146, 2008. 